\section{Anthocyanin Levels in Nine Lettuce (Lactuca sativa) Cultivars: Influence of Planting Date and Relations among Analytic, Instrumented, and Visual Assessments of Color}

\author{
Aparna Gazula ${ }^{1}$ \\ Department of Horticulture and Crop Science, The Ohio State University, Ohio \\ Agricultural Research and Development Center, Wooster, OH 44691-4096
}

Matthew D. Kleinhenz ${ }^{2}$ and Joseph C. Scheerens

Department of Horticulture and Crop Science, The Ohio State University, Ohio Agricultural Research and Development Center, 1680 Madison Avenue, Wooster, OH 44691-4096

\section{Peter P. Ling}

Department of Food, Agricultural and Biological Engineering, The Ohio State University, Ohio Agricultural Research and Development Center, 1680 Madison Avenue, Wooster, OH 44691-4096

Additional index words. antioxidant, colorimeter, crop quality, sensory evaluation, spectroradiometer

\begin{abstract}
Leaf samples collected from field plots of nine lettuce cultivars established in the early (ES) and late (LS) summer of 2002 and 2003 in Celeryville, Ohio, were subjected to spectrophotometric measurement of anthocyanin concentrations or color analysis based on colorimeter and spectroradiometer readings and human panelist ratings. Interactions among year (Y), transplanting date (TD), and cultivar (C) main effects for anthocyanin concentration were significant as a result of shifts in response magnitude but not direction. Anthocyanin levels were higher after LS than ES transplanting regardless of $Y$ and $C$. The effects of TD were pronounced in 2002, when differences in average daily temperature between ES and LS transplantings tended to be larger. Also, regardless of $Y$ and TD, anthocyanin levels followed the pattern 'Impuls' $>$ 'OOC 1441' $>$ 'Valeria' > 'OOC1426' $>$ 'Lotto' > 'SVR 9634' > 'OOC 1434' = 'OOC 1310'> 'Cireo'. Treatment-based color differences were also evident in colorimeter and spectroradiometer readings. Also, panelists differentiated samples grown in 2003 based on red color intensity. Correlations between analytic and instrumented and human panelist-based measures suggest instrumented assessments of red coloration may serve as proxies for direct measures of anthocyanin levels or human panelist ratings, particularly if the aim is to establish color differences between major experimental groups and assign quantitative, repeatable values to red color intensity.
\end{abstract}

\footnotetext{
Received for publication 25 June 2006. Accepted for publication 29 Sept. 2006

Salaries and research support provided in part by state and federal funds appropriated to the Ohio Agricultural Research and Development Center, The Ohio State University. Work also supported in part by grants from the Ohio Vegetable and Small Fruit Research and Development Program.

We thank Dr. Jeannine Delwiche, Dr. Senay Ozgen, Dr. John Streeter, Dr. Annette Wszelaki, Sonia Walker, Rachel Liggett, Rick Callendar, and staff of the Ohio Agricultural Research and Development Center Muck Crops Research Station in Celeryville, Ohio, and Extension Vegetable Physiology Lab in Wooster, Ohio, for their important contributions. Use of trade names does not imply endorsement of the products named nor criticism of similar ones not named. ${ }^{1}$ Currently, Graduate Research Associate, Horticultural Sciences Department, University of Florida, 1143 Fifield Hall, P.O. Box 110690, Gainesville, FL 32611-0690.

${ }^{2}$ To whom reprint requests should be addressed; e-mailkleinhenz.1@osu.edu.
}

Although nutritional value, texture, size, shape, flavor, and freedom from defects are major indicators of lettuce crop quality (Arthey, 1975), leaf color is particularly important because it is often the first trait that registers with potential consumers or buyers (Ryder, 1999). In addition to their key roles in the plant (Burger and Edwards, 1996; Chalker-Scott, 1999; Choinski and Johnson, 1993; Cooper-Driver and Bhattacharya, 1998; Harborne, 1988; Leng and Qi, 2003; Nogués et al., 1998; Woodall and Stewart, 1998) and, possibly, human health (Keevil et al., 2000; Mazza and Miniati, 1993; Wang et al., 1999), the amounts and distributions of chlorophylls and anthocyanins contribute significantly to leaf color and product appeal.

That anthocyanin levels appear to be driven by genetics, temperature, and light (Kader et al., 1974) has been best demonstrated in fruit and floricultural crops (Dela et al., 2003; Katz and Weiss, 1999; Nunes et al., 2003; Nunez et al., 2004; Poll et al., 2003; Shvarts et al., 1997b; Solovchenko and Schmitz-Eiberger, 2003), although other evidence suggests these factors also influence anthocyanin levels in lettuce (Gazula et al., 2005; Kader et al., 1974; Kleinhenz et al., 2003a; Timberlake and Bridle, 1975). Still, given that anthocyanins vary widely in makeup and crop and tissue specificity (Timberlake and Bridle, 1975) and results from controlled environment studies (Dela et al., 2003; Katz and Weiss, 1999; Nunes et al., 2003; Shvarts et al., 1997a) may poorly predict crop responses in field production (Christie et al., 1994; Leng and Qi, 2003; Pietrini and Massacci, 1998; Pietrini et al., 2002; Shvarts et al., 1997a, 1997b; Wang and Zheng, 2001), additional tests of the genetic and environmental controls of anthocyanin levels in lettuce are needed. Lettuce is planted in many months annually with crops experiencing a range of environmental conditions. However, little is reported regarding seasonal (i.e., transplanting date) effects on anthocyanin levels in lettuce.

Anthocyanin levels are commonly measured using spectrophotometry (Gazula et al., 2005), paper chromatography, thin-layer chromatography, and high-performance liquid chromatography (Harborne and Grayer, 1988), methods that are expensive, timeconsuming, and require destructive sampling (Gamon and Surfus, 1999). Less destructive and more resource-efficient estimates of anthocyanin levels in leaf tissues have been attempted with colorimetry (Gonnet, 1998; Katori et al., 2002) and leaf reflectance (Gamon and Surfus, 1999), although not in lettuce. Estimates of anthocyanin levels based on reflectometer readings may have promise (Gamon and Surfus, 1999), but the reliability of such estimates is thought to vary with species and the presence of copigments (Sims and Gamon, 2002). Yet, correlations between direct but costly and destructive measures of anthocyanin levels and indirect but efficient and nondestructive estimates in lettuce would have important practical and scientific applications and are, therefore, worth testing.

More powerful still would be relationships between direct or indirect instrumented estimates of anthocyanin levels and ratings of leaf coloration provided by human panelists. Photographs and digital images combined with conjoint or cluster analysis have been successfully applied in evaluations of consumer responses to various external characteristics of apples (Cliff et al., 2002), geraniums (Behe et al., 1999), and Satsuma mandarins (Campbell et al., 2004). Earlier, colorimeter readings were related to a color chart to help substitute instrumented measures for color visualization (Voss, 1992). Such evaluations reinforce that the influence of visually based traits of fresh horticultural products on consumer preferences or habits can be quantified. These evaluations also suggest similar approaches may help improve understanding of lettuce crop managementconsumer quality relationships, facilitate 
cultivar development, and provide other benefits. For lettuce, more information is needed to understand the genetic and environmental controls of anthocyanin levels and to use either anthocyanin levels measured analytically or descriptions of color obtained with instruments as potential proxies for human assessments of leaf color (i.e., initial perceptions of product quality). Therefore, we set out to: 1) document the effects of field transplanting date (early summer-June/July and late summer-August/September) on anthocyanin concentrations in nine lettuce cultivars varying in red coloration; 2) assess panelists' abilities to differentiate samples of these cultivars grown in 2003 based on red coloration; and 3) test relationships among visual (human panelist), instrumented (colorimeter, spectroradiometer), and analytic (spectrophotometric) assessments of red coloration and anthocyanin concentrations using fieldgrown lettuce.

\section{Materials and Methods}

\section{Lettuce growth}

Thirty day-old seedlings of 'Cireo', 'Lotto', 'Valeria', 'Impuls' (Nunhems Seed, Haelen, The Netherlands), 'SVR 9634', 'OOC 1434', 'OOC 1426', 'OOC 1310', and 'OOC 1441' (Sunseeds Co., Parma, Idaho) lettuce cultivars representing a range of pigmentation from green to dark red were planted in early and late summer of 2002 and 2003 at the Ohio Agricultural Research and Development Center (OARDC) Muck Crops Research Station in Celeryville, Ohio. Plots were harvested $30 \mathrm{~d}$ after transplanting. Transplanting and harvest dates for early (ES) and late summer (LS) plots were: ES 2002: 27 June, 27 July; ES 2003: 20 June, 20 July; LS 2002: 1 Sept., 30 Sept.; and LS 2003; 15 Aug., 15 Sept. Two weeks before transplanting, soil in the experimental area was prepared by moldboard plowing, disking, and fertilizer $\left(95.2 \mathrm{~kg} \cdot \mathrm{ha}^{-1} \mathrm{~N}, 42.0\right.$ $\mathrm{kg} \cdot \mathrm{ha}^{-1} \mathrm{P}$, and $79.0 \mathrm{~kg} \cdot \mathrm{ha}^{-1} \mathrm{~K}$ via $17-17-17$; Country Star Coop., New Washington, Ohio) application and incorporation.

Seedlings were placed into $4.6 \mathrm{~m} \times 1.5-\mathrm{m}$, three-row plots arranged in a randomized complete block design with six replications per cultivar per transplanting date using a cone-type transplanter. Rows were separated by $0.5 \mathrm{~m}$ and plants within rows by $0.3 \mathrm{~m}$. Standard pest management strategies based on scouting, thresholds, and application of labeled pesticides were used. Plots were provided with $2.13 \mathrm{~cm}, 2.54 \mathrm{~cm}, 2.54 \mathrm{~cm}$, and $3.56 \mathrm{~cm}$ of irrigation on 27 June 2002, 17 July 2002, 5 Sept. 2002, and 11 Sept. 2002 , respectively.

\section{Direct measures of anthocyanin levels and instrumented and human panelist assessments of leaf color}

The experimental approach used here emphasized using individual leaf samples in multiple measures, thereby strengthening the opportunity to explore correlations among these measures. Thirty days after transplanting, samples consisting of the intact, aboveground portion of four different plants were collected from the center row of each field plot (six replications per cultivar per transplanting date), placed in plastic bags, and transferred while over ice to the OARDC in Wooster, Ohio, within $2 \mathrm{~h}$ of removal from the field. Samples were held in dark storage at $7{ }^{\circ} \mathrm{C}$ until further subsampling or measurements were completed within $48 \mathrm{~h}$ of foliar sample removal from the field. Individual leaf samples were used in one or more measures as described subsequently.

Anthocyanin measurement. Within $24 \mathrm{~h}$ after harvest, tissue was removed from leaf number four (fourth leaf from the outer whorl) of three plants per plot as in Kleinhenz et al. (2003a) and held in dark storage at $-20{ }^{\circ} \mathrm{C}$ until pigment extraction. A portion of the same leaf was used to calculate tissue moisture content by weight difference before and after drying at $70{ }^{\circ} \mathrm{C}$ for $72 \mathrm{~h}$.

Pigment extraction and quantification was completed as described previously (Kleinhenz et al., 2003a) with three exceptions. Absorbance readings corresponding to anthocyanin pigments were measured at $530 \mathrm{~nm}$. This wavelength led to maximum absorption in wavelength scans taken with a HP 8452 Diode array spectrophotometer (HewlettPackard Co., Palo Alto, Calif.) and has also been used previously (Mancinelli, 1990; Oren-Shamir and Levi-Nissim, 1997; Pietrini et al., 2002). Absorbance readings were taken using a Beckman Coulter DU 640 spectrophotometer (Beckman Coulter, Fullerton, Calif.). Finally, standard curves were developed using high-performance liquid chromatography grade cyanidin 3-glucoside (Chromadex, Santa Ana, Calif.) with a molar absorptivity of 26,900 and a molecular weight of 449.2 (Giusti and Wrolstad, 2002).

Instrumented assessments of leaf color. In 2003, colorimeter and spectroradiometer readings were taken on leaf number 5 (fifth leaf from the outer whorl) of the same three foliar samples also used for anthocyanin analysis. For both instruments, a single reading was taken on the adaxial surface of each leaf at the same location from which samples were drawn for anthocyanin measures on leaf number 4 (midway between the acropetal and basipetal ends and within $2.54 \mathrm{~cm}$ of the margin) within $24 \mathrm{~h}$ after removal from the field.

Colorimeter readings. External lettuce leaf color was measured using a Minolta Chromameter (model CR-100; Ramsey, N.J.) in CIE L*, $a^{*}, b^{*}$ mode with an 8-mm measuring aperture using CIE Standard Illuminant $\mathrm{C}$. The instrument was calibrated with the Minolta Calibration standard white reflector plate before sampling lettuce leaves. Whole-leaf samples were placed on a white background and single readings were taken on the upper surface of each leaf midway between the apical and basal ends with the handheld unit. Individual leaves were then positioned between two paper towels moistened with distilled water in a plastic bag and held on ice until all readings were completed. $L^{*}, a^{*}, b^{*}$ readings were transformed to those of the L, a, b color space and finally to hue angle and chroma according to Setser (1984) and as recommended by McGuire (1992).

Spectroradiometer readings. After colorimeter readings, reflectance on the adaxial surface of the leaf was recorded at $635 \mathrm{~nm}$ in the visible range using a spectroradiometer (PS-2; ASD, Boulder, Colo.). The machine was calibrated with the white reference. The whole-leaf sample was placed within the clamps of the integrating sphere and leaf reflectance measured.

Human panel color ratings.

Panel training. Visual estimates of anthocyanin levels in lettuce leaves (based on red color intensity and distribution) were provided by a panel of 20 volunteers (11 males) aged 20 to 64 years previously untrained but familiar with vegetable product sensory evaluation (Kleinhenz et al., 2003a, 2003b; Wszelaki et al., 2005a, 2005b). All panelists attended a 1-h training session. During this session, investigators and panelists discussed criteria necessary to distinguish differences in red color distribution and intensity among freshly harvested, growth chamber-grown reference lettuce leaves representing a range of red coloration. Panelists were asked to focus solely on red-pigmented tissues within each leaf when scoring red intensity (i.e., to disregard variability in pigment distribution when scoring intensity). Copigmented leaves having areas with relatively low anthocyanin levels coupled with relatively high chlorophyll levels were also illustrated during the training session (Strack and Wray, 1989). Panelists were advised to consider the presence of the resulting brown color as evidence of underlying redness and to proceed with rating intensity as discussed earlier.

Sample collection. The fourth foliar sample collected from the field in 2003 as

Table 1. Analysis of variance for the impact of year, transplanting date, and cultivar on anthocyanin concentrations in leaves of lettuce (Lactuca sativa L.) grown at the Ohio Agricultural Research and Development Center Muck Crops Research Station in Celeryville, Ohio, in 2002 and 2003.

\begin{tabular}{lcc}
\hline Source & $\mathrm{df}^{z}$ & $\begin{array}{c}\text { Anthocyanin } \\
\text { concn. }\end{array}$ \\
\hline Year (Y) & 1 & $* *$ \\
Transplanting date (TD) & & $* *$ \\
Cultivar (C) & 1 & $* *$ \\
$\mathrm{Y} \times \mathrm{TD}$ & 8 & $* *$ \\
$\mathrm{Y} \times \mathrm{C}$ & 1 & $* *$ \\
$\mathrm{TD} \times \mathrm{C}$ & 8 & $* *$ \\
\hline
\end{tabular}

${ }^{\mathrm{z}} \mathrm{df}=$ degrees of freedom.

yTransplanting dates are early summer and late summer.

${ }^{x}$ Cultivars are Cireo, Lotto, Valeria, Impuls, SVR 9634, OOC 1434, OOC 1426, OOC 1310, and OOC 1441.

**Significant at $P \leq 0.01$. 
described previously was used in the evaluation. Foliar samples were held in dark storage at $7{ }^{\circ} \mathrm{C}$ until panel testing $48 \mathrm{~h}$ after sample removal from the field. One hour before evaluation, all six foliar samples for each cultivar were rinsed with distilled water and leaf number four was removed and rerinsed. Thereafter, four leaves comprising the most uniform group based on size and red coloration were chosen for each cultivar, assigned a replicate value (1-4), and transferred to the evaluation site.
Evaluation procedure. All methods for testing human subjects were approved by the Office of Responsible Research Practices at The Ohio State University before testing began. The testing room was illuminated by artificial fluorescent light $\left(100 \mu \mathrm{mol} \cdot \mathrm{m}^{-2} \cdot \mathrm{s}^{-1}\right.$ at sample height) and the curtains were drawn to prevent natural daylight from entering the room. Thirty minutes before evaluation, samples were placed in the center of $18 \mathrm{~cm} \times$ 23-cm white Styrofoam trays prelabeled with unique, randomly selected three-digit codes.

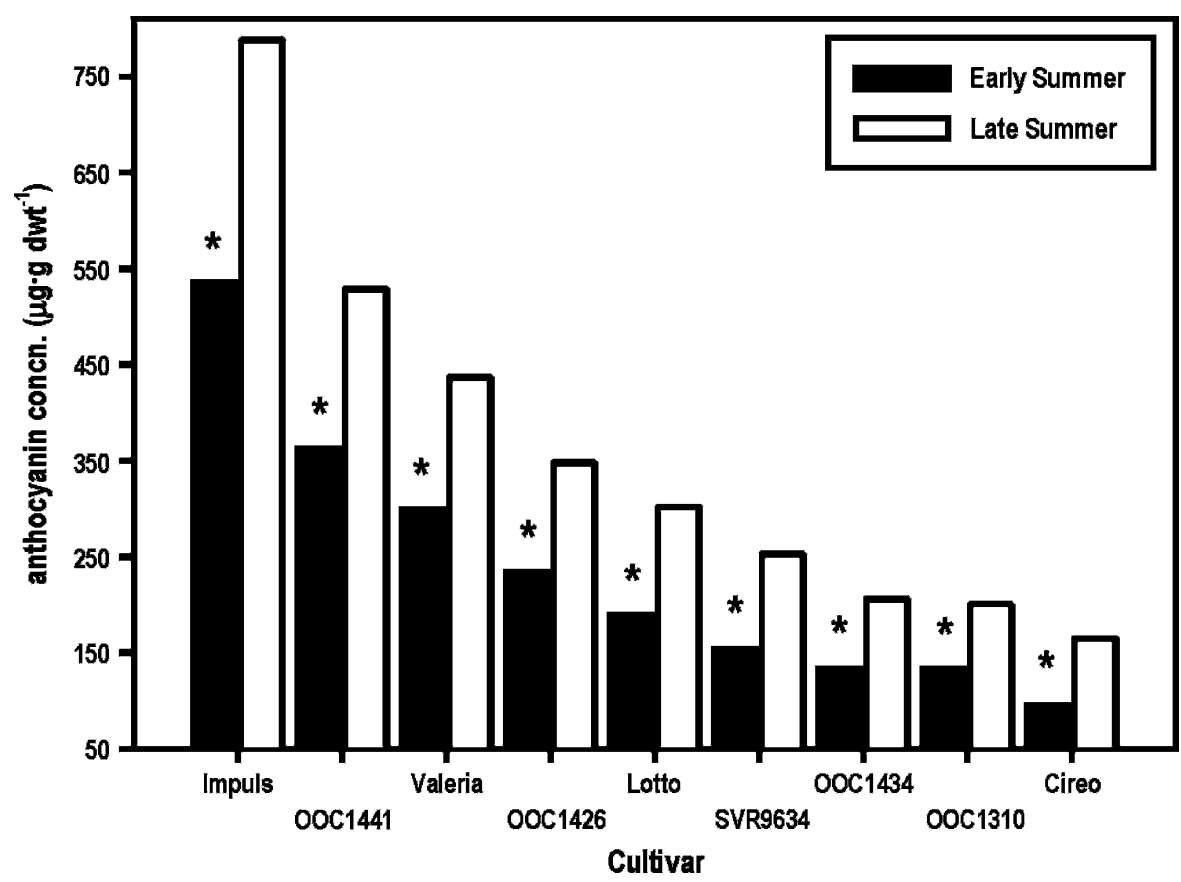

Fig. 1. Effect of transplanting date on anthocyanin concentrations in leaf number four (fourth leaf from outer whorl) of nine lettuce (Lactuca sativa L.) cultivars grown at the Ohio Agricultural Research and Development Center Muck Crops Research Station in Celeryville, Ohio, in 2002 and 2003. Samples were collected $30 \mathrm{~d}$ after transplanting. Asterisks $(*)$ indicate transplanting date significantly affected anthocyanin concentrations in the cultivars shown according to Fisher least significant difference test $(\alpha=0.01)$. Values shown are the 2002-2003 mean of 36 observations per cultivar.

Trays were then placed at $15-\mathrm{cm}$ intervals around the perimeter of a $5 \mathrm{~m} \times 1.5$-m lightly colored wooden table.

Instructions given to panelists during the introductory session were repeated before the test. The evaluation lasted $\approx 30 \mathrm{~min}$ with panelists scoring samples at self-selected paces and in a predetermined order, which was random within and among judges. According to techniques described by Land and Shepherd (1984) and Meilgaard et al. (2000), panelists scored each sample for red intensity by placing a vertical mark on a 165 $\mathrm{mm}$ horizontal scale at the position that best described their opinion of the leaf characteristic. Intensity scores were determined by measuring the position of vertical marks from the left anchor point of the scale.

\section{Data analysis}

All statistics were completed using Statistical Analysis System v. 7 for Windows (SAS Institute, Cary, N.C.). Year (Y), transplanting date (TD), and cultivar (C) effects were estimated using fully specified model statements and considered significant when $P \leq 0.01$. Treatment effects were further analyzed using $t$ tests (least significant difference) with $\alpha=0.01$.

\section{Results}

Anthocyanin concentrations. Anthocyanin concentrations in lettuce leaf tissue were influenced by $\mathrm{Y}, \mathrm{TD}$, and $\mathrm{C}$ and their interaction (Table 1). Significant interactions resulted primarily from changes in magnitude, not direction, of the response of anthocyanin levels at contrasting levels of main effects. A focus on main effects reveals that the mean anthocyanin concentration $\left(\mu \mathrm{g} \cdot \mathrm{g}^{-1}\right.$ dwt) in 2002 (351.3) significantly exceeded that in 2003 (244.0), late summer transplanting led to a significantly greater anthocyanin concentration (358.6) than early summer

Table 2. Cultivar effects, within transplanting date, on mean red color intensity (measured on a relative scale from $0-165 \mathrm{~mm}$ ), hue angle $\left(^{\circ}\right)$, and chroma in leaves of lettuce (Lactuca sativa L.) grown at the Ohio Agricultural Research and Development Center Muck Crops Research Station in Celeryville, Ohio, in 2003.

\begin{tabular}{|c|c|c|c|c|c|c|c|c|}
\hline \multirow[b]{3}{*}{ Cultivar } & \multicolumn{8}{|c|}{ Transplanting date } \\
\hline & \multicolumn{4}{|c|}{ Early summer } & \multicolumn{4}{|c|}{ Late summer } \\
\hline & $\begin{array}{l}\text { Anthocyanin } \\
\left(\mu \mathrm{g} \cdot \mathrm{g} \mathrm{dwt} \mathrm{d}^{-1}\right)^{\mathrm{z}, \mathrm{y}}\end{array}$ & $\begin{array}{l}\text { Red color } \\
\text { intensity }^{\mathrm{x}, \mathrm{w}}\end{array}$ & $\begin{array}{l}\text { Hue angle } \\
\left({ }^{\circ}\right)^{\mathrm{v}, \mathrm{u}}\end{array}$ & Chroma $^{\mathrm{v}, \mathrm{t}}$ & 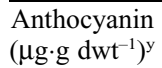 & $\begin{array}{l}\text { Red color } \\
\text { intensity }^{\mathrm{x}, \mathrm{w}}\end{array}$ & $\begin{array}{l}\text { Hue angle } \\
\left({ }^{\circ}\right)^{\mathrm{v}}\end{array}$ & Chroma $^{\vee}$ \\
\hline Cireo & $115.33 \mathrm{~h}$ & $\mathrm{~s}^{\mathrm{s}}$ & $133.18 \mathrm{a}$ & $18.02 \mathrm{f}$ & $155.88 \mathrm{~h}$ & - & $115.69 \mathrm{a}$ & $40.16 \mathrm{~d}$ \\
\hline Impuls & $401.40 \mathrm{a}$ & $136 \mathrm{a}$ & $6.59 \mathrm{f}$ & $50.51 \mathrm{a}$ & $493.56 \mathrm{a}$ & $141 \mathrm{a}$ & $12.26 \mathrm{f}$ & $56.67 \mathrm{a}$ \\
\hline Lotto & $192.30 \mathrm{e}$ & $90 \mathrm{c}$ & $10.01 \mathrm{ef}$ & $27.05 \mathrm{~d}$ & $261.14 \mathrm{~d}$ & $93 \mathrm{~d}$ & $28.15 \mathrm{~d}$ & $38.10 \mathrm{e}$ \\
\hline OOC 1310 & $143.29 \mathrm{~g}$ & $46 \mathrm{~d}$ & $40.83 \mathrm{~b}$ & $13.57 \mathrm{~g}$ & $187.62 \mathrm{~g}$ & $34 \mathrm{e}$ & $44.40 \mathrm{~b}$ & $17.09 \mathrm{~h}$ \\
\hline OOC 1426 & $248.55 \mathrm{~d}$ & $132 \mathrm{a}$ & $13.28 \mathrm{e}$ & $26.46 \mathrm{~d}$ & $284.62 \mathrm{c}$ & $125 \mathrm{~b}$ & $9.59 \mathrm{~g}$ & $35.81 \mathrm{f}$ \\
\hline OOC 1434 & $144.50 \mathrm{~g}$ & $90 \mathrm{c}$ & $31.22 \mathrm{c}$ & $12.68 \mathrm{~g}$ & $193.98 \mathrm{f}$ & $89 \mathrm{~d}$ & $40.03 \mathrm{c}$ & $16.18 \mathrm{~h}$ \\
\hline OOC 1441 & $282.22 \mathrm{~b}$ & $112 \mathrm{~b}$ & $7.74 \mathrm{f}$ & $39.02 \mathrm{~b}$ & $305.00 \mathrm{~b}$ & $106 \mathrm{c}$ & $8.58 \mathrm{~g}$ & $45.71 \mathrm{~b}$ \\
\hline SVR 9634 & $165.09 \mathrm{f}$ & $35 \mathrm{~d}$ & $29.02 \mathrm{c}$ & $24.65 \mathrm{e}$ & $239.12 \mathrm{e}$ & $45 \mathrm{e}$ & $29.35 \mathrm{~d}$ & $25.52 \mathrm{~g}$ \\
\hline Valeria & $274.35 \mathrm{c}$ & $107 \mathrm{~b}$ & $17.31 \mathrm{~d}$ & $32.86 \mathrm{c}$ & $303.48 \mathrm{~b}$ & $106 \mathrm{c}$ & $16.82 \mathrm{e}$ & $42.88 \mathrm{c}$ \\
\hline $\begin{array}{c}\text { Least significant } \\
\text { difference }_{0.01}\end{array}$ & 6.05 & 1.4 & 4.27 & 1.78 & 5.69 & 1.2 & 2.65 & 2.05 \\
\hline
\end{tabular}

${ }^{\mathrm{z}}$ Numbers in the same column followed by the same letter are not significantly different according to Fisher least significant difference test $(\alpha=0.01)$.

${ }^{y}$ Number of data points per cultivar used in statistical analysis $=18$.

${ }^{\mathrm{x}}$ Number of data points per cultivar used in statistical analysis $=80$.

wDistance (mm) from left-most anchor on a 165-mm-long horizontal line scale bearing the caption "light red."

Number of data points per cultivar used in statistical analysis $=18$.

uHue expressed in degrees of a circle: $0^{\circ}=$ pure red, $90^{\circ}=$ pure yellow, $180^{\circ}=$ pure green, $270^{\circ}=$ pure blue.

${ }^{t}$ Chroma values indicate color saturation; higher values indicate greater color intensity.

${ }^{\mathrm{s}}$ Cireo lacks visible red pigment. Therefore, red color intensity was not scored. 
transplanting (236.7), and that, regardless of $\mathrm{Y}$ and TD, mean varietal anthocyanin concentrations tended to follow the pattern 'Impuls' > 'OOC 1441'> 'Valeria' > 'OOC'1426' > 'Lotto' > 'SVR 9634'> 'OOC 1434' = 'OOC 1310' > 'Cireo' (Fig. 1).

Panel scores of red color intensity. In 2003, judges distinguished cultivars based on red color intensity (anthocyanin concentration) regardless of TD (Table 2). 'Impuls' received the highest intensity scores and either 'SVR9634' or 'OOC1310' the lowest (Table 2). Relative to scores for ES-planted samples, scores for LS-planted samples increased in three cultivars, decreased in three cultivars, and remained unchanged in two cultivars; however, changes in panel scores from ES to LS were not significant (data not shown).

Direct and indirect assessments of color. Cultivars were also distinguishable by colorimetry and spectroradiometry as hue angle and chroma values differed significantly among cultivars (Table 2) and a wide range of reflectance values was observed in 2003 (Fig. 2). Regardless of TD, 'Cireo' had the highest hue angle and 'Impuls' the highest chroma (Table 2). Cultivars ranking low, medium, or high for red color intensity, hue angle, or chroma after ES transplanting in 2003 tended to retain their relative ranking after LS transplanting.

Significant quadratic relationships were found between instrumented (spectroradiometer, colorimeter) and analytic (spectrophotometer) measures taken in 2003 (Fig. 2). Increases in average reflectance at $635 \mathrm{~nm}$ and chroma were associated with increases in anthocyanin concentrations (Fig. 2A, C), whereas increases in hue angle were associated with decreases in anthocyanin level (Fig. 2B).

Interesting quadratic relationships were also found between spectroradiometer, colorimeter, and spectrophotometer values and human panelists' scores in 2003 (Fig. 3). Increases in average reflectance at $635 \mathrm{~nm}$ and anthocyanin levels were associated with increases in red color intensity scores (Fig. $3 \mathrm{~A}, \mathrm{C}$ ), whereas increases in hue angle were associated with decreases in red color intensity scores (Fig. 3B).

Twelve additional plots were developed to elucidate potential TD effects on the relationships evident in Figures 2 and 3, yet the shape and statistics of these plots revealed that TD did not alter these relationships (data not shown). The shapes and slopes of the 12 regression lines changed little relative to those shown in Figures 2 and 3. Also, seven of the $12 \mathrm{R}^{2}$ values were within 0.03 of the values shown in Figures 2 and 3 (data not shown). However, the $\mathrm{R}^{2}$ value in Figure $2 \mathrm{~B}$ increased to 0.70 (ES) and 0.59 (LS) and the $\mathrm{R}^{2}$ value in Figure 2C increased to 0.91 (ES) when subsets of the data shown in Figure 2 were plotted.

\section{Discussion and Conclusions}

Anthocyanin concentrations. Genetics, temperature, and light influence anthocyanin
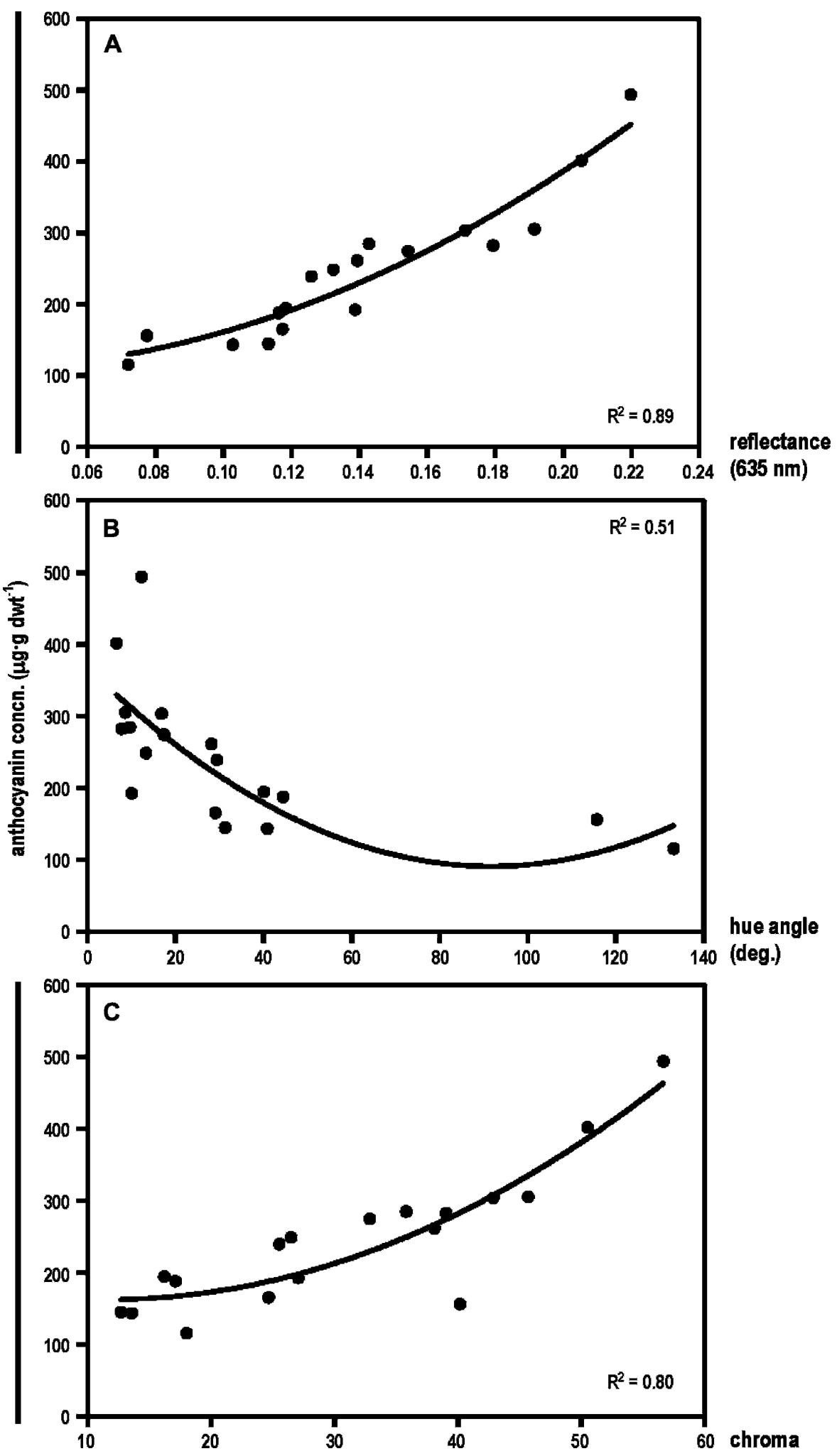

Fig. 2. Relationships between (A) reflectance at $635 \mathrm{~nm}$ measured with a spectroradiometer, and (B) hue angle and (C) chroma measured with a colorimeter and anthocyanin concentrations measured with a spectrophotometer for leaves of nine lettuce cultivars grown at the Ohio Agricultural Research and Development Center Muck Crops Research Station in Celervyille, Ohio, in 2003.

accumulation in lettuce (Gazula et al., 2005; Kleinhenz et al., 2003a). In this study, mean daily air temperatures tended to be higher in 2002 than in 2003 and after ES versus LS transplanting (Fig. 4), contributing to the higher anthocyanin levels observed in 2003 and after LS transplanting. However, cultivar-specific tests of the $\mathrm{Y}$ effect revealed $\mathrm{Y}$ significantly affected anthocyanin levels in only four of nine cultivars (data not shown). Interestingly, these four cultivars contained mean experiment-wide anthocyanin concentrations 


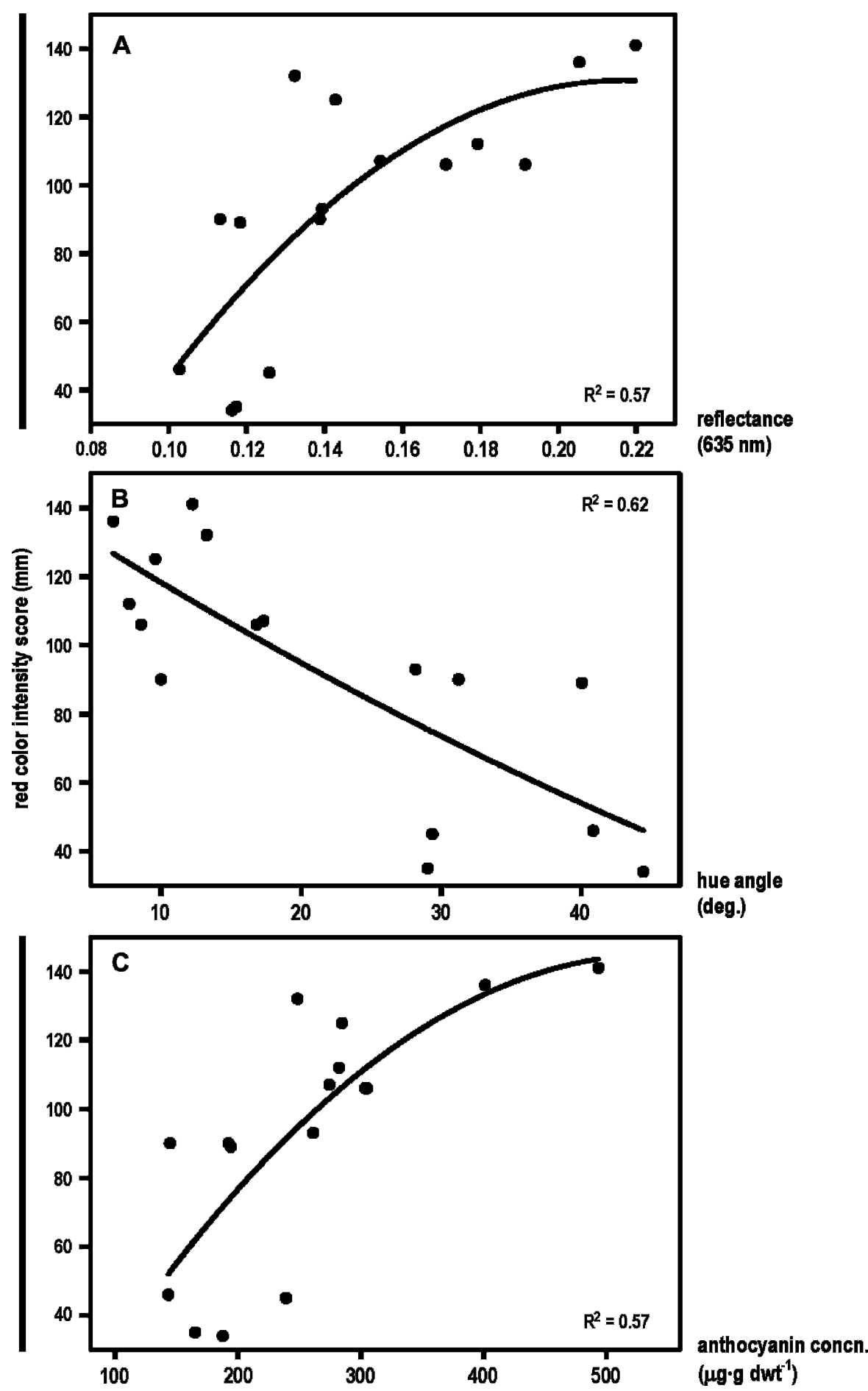

Fig. 3. Relationships between (A) reflectance at $635 \mathrm{~nm}$ measured with a spectroradiometer, (B) hue angle and $(\mathbf{C})$ chroma measured with a colorimeter and red color intensity scores $(0-165-\mathrm{mm}$ scale $)$ given by human panelists for leaves of nine lettuce cultivars grown at the Ohio Agricultural Research and Development Center Muck Crops Research Station in Celervyille, Ohio, in 2003.

exceeding $264.0 \mu \mathrm{g} \cdot \mathrm{g} \mathrm{dwt} \mathrm{d}^{-1}$. Mean anthocyanin levels in 'Cireo', 'OOC 1310', 'OOC 1434', and 'SVR 9634' (124.1-205.0 $\mu \mathrm{g} \cdot \mathrm{g}$ $\mathrm{dwt}^{-1}$ in 2002 and 135.6-202.1 $\mu \mathrm{g} \cdot \mathrm{g} \mathrm{dwt}^{-1}$ in 2003) were lowest experiment-wide and displayed little response to changes in temperature and other factors between 2002 and 2003. Anthocyanin levels in 'Lotto' and 'OOC 1426' (264.0-314.1 $\mu \mathrm{g} \cdot \mathrm{g} \mathrm{dwt} \mathrm{d}^{-1}$ in 2002 and 226.7-266.6 $\mu \mathrm{g} \cdot \mathrm{g} \mathrm{dwt} \mathrm{din}^{-1}$ in 2003) transplanting exceeded those after ES transplanting by $32 \%$ to $43 \%$ with an average ES to LS transplanting increase of 35\% (Fig. 1). Regardless of Y, daily average temperatures tended to be higher in ES than LS transplantings, particularly during the 10 days immediately before plant harvest (Fig. 4). However, LS plots may also have experienced lower light levels than ES plots. Light is essential for anthocyanin synthesis (Reay, 1999; Weiss and Halevy, 1991) and shaded lettuce may contain less anthocyanin (Kleinhenz et al., 2003a). However, moderatelow temperatures are thought to separately and specifically trigger anthocyanin synthesis, not simply enhance its regulation after gene expression (Shvarts et al., 1997a). Therefore, under normal growth conditions, temperature, not light, may exert the strongest influence on anthocyanin concentrations in lettuce, an assertion supported by data from cocoplum (Chrysobalanus icaco) leaves (Levi-Nissim et al., 2003) and our own data; the suppressive effect that low light levels may have had in our LS samples seems to have been overcome by the enhancement effect of low temperature in the same samples. Our data suggest lettuce cultivars genetically predisposed to contain higher anthocyanin concentrations respond most strongly to annual or seasonal temperature patterns.

Associations among instrumented assessments of color, anthocyanin levels, and panelists' scores of red color intensity. In addition to genotype and TD effects on anthocyanin levels, three types of associations were tested in this work. In the first, physical, instrumented assessments of color made with a colorimeter and spectroradiometer were compared with direct measures of anthocyanin concentration. In the second and third, direct measures of anthocyanin levels and instrumented assessments of color were compared with human panelists' scores of red color intensity. Relationships evident in Figures 2 and 3 appear worthy of exploitation in additional research, particularly that involving a larger set of genotypes varying only in anthocyanin production potential. Leaf reflectance (spectroradiometer, Fig. 2A) and chroma (colorimeter, Fig. 2C) values strongly correlated with anthocyanin levels. Also, although weaker, associations between spectroradiometer, colorimeter, and spectrophotometer values and human panelists' ratings (Fig. 3) were encouraging. Interestingly, anthocyanins were found in 'Cireo' but panelists detected no redness in this cultivar and, therefore, did not score its red color intensity. Although the visualization of redness is mitigated by many factors, these results suggest the threshold level of anthocyanins needed for panelists to see red is more than that reported here for 'Cireo'.

Overall, the data underscore the potential for rapid, inexpensive, and potentially nondestructive instrument-based assessments of red coloration to serve as proxies for direct measures of anthocyanin levels and human panelist red color intensity scores, particularly 


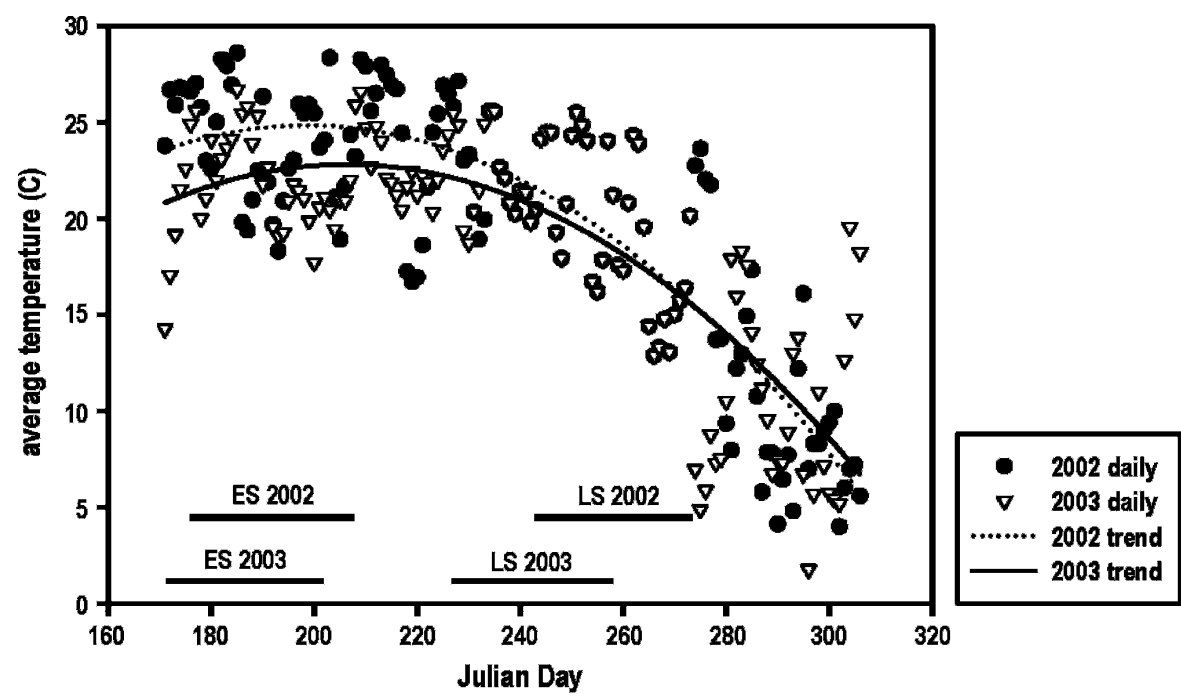

Fig. 4. Average air temperature $\left({ }^{\circ} \mathrm{C}\right)$ for 20 June (Julian day 171) to 30 Sept. (Julian day 273) recorded at the Ohio Agricultural Research and Development Center Muck Crops Research Station in Celeryville, Ohio, in 2002 and 2003. Bars topped by ES or LS and year indicate early (ES) and late summer (LS) lettuce transplanting-growth-harvest periods.

if the aim is to establish color differences between major experimental groups and assign quantitative, potentially repeatable values to red color intensity. The data also point to careful selection of genotypes and growing conditions as key to the success of additional work in this area. Seeking to verify whether similar relationships exist in lettuce samples grown under a different set of conditions, anthocyanin levels, and spectroradiometer readings were taken in a subset ('Lotto', 'Valeria', 'Impuls') of cultivars used in the current study and subjected to contrasting growing temperatures in environmentally controlled chambers (Gazula et al., 2005). A positive, curvilinear relationship $\left(\mathrm{R}^{2}=0.97\right)$ similar to that shown in Figure 2A was found (data not shown). Lettuce breeders, product development specialists, and other sectors of the lettuce productiondistribution-sale continuum are likely to benefit from clarification of relationships reported here.

\section{Literature Cited}

Arthey, V.D. 1975. Quality of horticultural products. Wiley, N.Y.

Behe, B., R. Nelson, S. Barton, C. Hall, C.D. Safley, and S. Turner. 1999. Consumer preferences for geranium flower color, leaf variegation and price. HortScience 34:740-742.

Burger, J. and G.E. Edwards. 1996. Photosynthetic efficiency, and photodamage by UV and visible radiation, in red versus green leaf coleus varieties. Plant Cell Physiol. 37: 395-399.

Campbell, B.L., R.G. Nelson, R.C. Ebel, W.A. Dozier, J.L. Adrian, and B.R. Hockema. 2004. Fruit quality characteristics that affect consumer preferences for Satsuma mandarins. HortScience 39:1664-1669.

Chalker-Scott, L. 1999. Environmental significance of anthocyanins in plant stress responses. Photochem. Photobiol. 70:1-9.

Choinski, J.S., Jr. and J.M. Johnson. 1993. Changes in photosynthesis and water status of develop- ing leaves of Brachystegia spiciformis Benth Tree Physiol. 13:17-27.

Christie, P.J., M.R. Alfentio, and V. Walbot. 1994 Impact of low-temperature stress on general phenylpropanoid and anthocyanin pathways: Enhancement of transcript abundance and anthocyanin pigmentation in maize seedlings. Planta 194:541-549.

Cliff, M., W. Sanford, W. Wisner, and C. Hampson. 2002. Use of digital images for evaluation of factors responsible for visual preference of apples by consumers. HortScience 37:11271131.

Cooper-Driver, G.A. and M. Bhattacharya. 1998. Role of phenolics in plant evolution. Phytochemistry 49:1165-1174.

Dela, D., E. Or, R. Ovadia, A. Nissim-Levi, D Weiss, and M. Oren-Shamir. 2003. Changes in anthocyanin concentration and composition in 'Jaguar' rose flowers due to transient hightemperature conditions. Plant Sci. 164:333340.

Gamon, J.A. and J.S. Surfus. 1999. Assessing leaf pigment content and activity with a reflectometer. New Phytol. 143:105-117.

Gazula, A., M.D. Kleinhenz, J.G. Streeter, and A.R. Miller. 2005. Temperature and cultivar effects on anthocyanin and chlorophyll $\mathrm{b}$ concentrations in three related Lolla Rosso lettuce cultivars. HortScience 40:1731-1733.

Giusti, M.M. and R.E. Wrolstad. 2002. Characterization and measurement of anthocyanins by UV-visible spectroscopy. Unit F1.2. In: R.E. Wrolstad (ed.). Current protocols in food analytical chemistry. Wiley \& Sons, N.Y.

Gonnet, J.F. 1998. Colour effects of co-pigmentation of anthocyanins revisited. 1. A colorimetric definition using the CIELAB scale. Food Chem. 63:409-415.

Harborne, J.B. 1988. Introduction to ecological biochemistry. 3rd ed. Academic Press, London.

Harborne, J.B. and R.J. Grayer. 1988. The anthocyanins, p. 1-20. In: J.B. Harborne (ed.). The flavonoids. Advances in research since 1980. Chapman \& Hall, Cambridge.

Kader, A.A., J.M. Lyons, and L.L. Morris. 1974. Postharvest response of vegetables to preharvest field temperatures. HortScience 9:525527.
Katori, M., K. Watanabe, K. Nomura, and K. Yoneda. 2002. Cultivar differences in anthocyanin and carotenoid pigments in the petals of the flowering lotus (Nelumbo spp.). J. Jpn. Soc. Hort. Sci. 71:812-817.

Katz, A. and D. Weiss. 1999. Light regulation of anthocyanin accumulation and chalcone synthase gene expression in Petunia flowers. Isr. J. Plant Sci. 47:225-229.

Keevil, J.G., H.E. Osman, J.D. Reed, and J.D. Folts. 2000. Grape juice, but not orange juice or grapefruit juice, inhibits human platelet aggregation. J. Nutr. 130:53-56.

Kleinhenz, M.D., D.G. French, A. Gazula, and J.C. Scheerens. 2003a. Variety, shading and growth stage effects on pigment concentrations in lettuce grown under contrasting temperature regimens. HortTechnology 13:677-683.

Kleinhenz, M.D., J.C. Scheerens, D.M. Francis, T.J.K. Radovich, D.G. French, A. Gazula, A. Wszelaki, A. Sanchez-Vela, A.A.C. McIntyre, J. Delwiche, P. Ling, K. Amisi, and D.J. Doohan. 2003b. From farm to consumerlinking crop physiology and production with buyer-oriented quality. I. Veg. Acta Hort. 604:95-103.

Land, D.G. and R. Shepherd. 1984. Scaling and ranking methods, p. 141-177. In: J.R. Piggott (ed.). Sensory analysis of foods. Elsevier Applied Science Publ., N.Y.

Leng, P. and J.X. Qi. 2003. Effect of anthocyanin on David peach (Prunus davidiana Franch) under low temperature stress. Scientia Hort. 97:27-39.

Levi-Nissim, A., S. Kagan, R. Ovadia, and M. Oren-Shamir. 2003. Effects of temperature, UV-light and magnesium on anthocyanin pigmentation in cocoplum leaves. J. Hort. Sci. Biotechnol. 78:61-64.

Mancinelli, A.L. 1990. Interaction between light quality and light quantity in the photoregulation of anthocyanin production. Plant Physiol. 92:1191-1195.

Mazza, G. and E. Miniati. 1993. Anthocyanins in fruits, vegetables, and grains. CRC Press, Boca Raton, Fla.

Meilgaard, M., G.V. Civille, and B.T. Carr. 2000. Sensory evaluation techniques. CRC Press, Boca Raton, Fla.

McGuire, R.G. 1992. Reporting of objective color measurements. HortScience 27:1254-1255.

Nogués, S., D.J. Allen, J.L.L. Morison, and N.R. Baker. 1998. Ultraviolet-b radiation effects on water relations, leaf development, and photosynthesis in droughted pea plants. Plant Physiol. 117:173-181.

Nunes, M.C.N., J.P. Emond, and J.K. Brecht. 2003. Quality of strawberries as affected by temperature abuse during ground, in-flight and retail handling operations. Acta Hort. 604:239-246.

Nunez, V., M. Monagas, M.C. Gomez-Cordoves, and M. Bartolome. 2004. Vitis vinifera L. cv. Graciano grapes characterized by its anthocyanin profile. Postharvest Biol. Technol. 31: 69-79.

Oren-Shamir, M. and A. Levi-Nissim. 1997. UVlight effect on the leaf pigmentation of Cotinus coggygria 'Royal Purple'. Scientia Hort. 71:59-66.

Pietrini, F., M.A. Iannelli, and A. Massacci. 2002. Anthocyanin accumulation in the illuminated surface of maize leaves enhances protection from photo-inhibitory risks at low temperature, without further limitation to photosynthesis. Plant Cell Environ. 25:1251-1259.

Pietrini, F. and A. Massacci. 1998. Leaf anthocyanin content changes in Zea mays L. grown at low temperature: Significance for the relationship 
between the quantum yield of PS II and the apparent quantum yield of $\mathrm{CO} 2$ assimilation. Photosyn. Res. 58:213-219.

Poll, L., M.B. Petersen, and G.S. Nielsen. 2003. Influence of harvest year and harvest time on soluble solids, titrateable acid, anthocyanin content and aroma components in sour cherry (Prunus cerasus L. cv. 'Stevensbaer'). Eur. Food Res. Technol. 216:212-216.

Reay, P.F. 1999. The role of low temperatures in the development of the red blush on apple fruit ('Granny Smith'). Scientia Hort. 79:113-119.

Ryder, E.J. 1999. Introduction to the crops, p. 1-27. In: E.J. Ryder (ed.). Lettuce, endive and chicory. CAB International Publishing, N.Y.

Setser, C.S. 1984. Color: Reflections and transmissions. J. Food Qual. 6:183-197.

Shvarts, M., A. Borochov, and D. Weiss. 1997a. Low temperature enhances petunia flower pigmentation and induces chalcone synthase gene expression. Physiol. Plant. 99:67-72.

Shvarts, M., D. Weiss, and A. Borochov. 1997b. Temperature effects on growth, pigmentation and post harvest longevity of petunia flowers. Scientia Hort. 69:217-227.
Sims, D.A. and J.A. Gamon. 2002. Relationships between leaf pigment content and spectral reflectance across a wide range of species, leaf structures and developmental stages. Remote Sensing Environ. 81:337-354.

Solovchenko, A. and M. Schmitz-Eiberger. 2003. Significance of skin flavonoids for UV-Bprotection in apple fruits. J. Expt. Bot. 54:1977-1984.

Strack, D. and V. Wray. 1989. Anthocyanins, p. 325-356. In: P.M. Dey and J.B. Harborne (eds.). Methods in Plant Biochemistry. Vol 1. Plant Phenolics. Academic Press, San Diego, Calif.

Timberlake, C.F. and P. Bridle. 1975. The anthocyanins, p. 214-266. In: J.B. Harborne, T.J. Mabry, and H. Mabry (eds.). The Flavonoids. Part 1. Academic Press, N.Y.

Voss, D.H. 1992. Relating colorimeter measurement of plant color to the Royal Horticultural Society Colour Chart. HortScience 27:12561260.

Wang, H., M.G. Nair, G.M. Strasburg, Y. Chang, A.M. Booren, J.I. Gray, and D.L. DeWitt. 1999. Antioxidant and anti-inflammatory activities of anthocyanins and their aglycon, cyanidin, from tart cherries. J. Nat. Prod. 62:294-296.

Wang, S.Y. and W. Zheng. 2001. Effect of plant growth temperature on antioxidant capacity in strawberry. J. Agr. Food Chem. 49:4977-4982.

Weiss, D. and A.H. Halevy. 1991. The role of light reactions in the regulation of anthocyanin synthesis in Petunia corollas. Physiol. Plant. $81: 127-133$

Woodall, G.S. and G.R. Stewart. 1998. Do anthocyanins play a role in UV protection of the red juvenile leaves of Syzygium. J. Expt. Bot. 49:1447-1450.

Wszelaki, A.L., J.F. Delwiche, S.D. Walker, R.E. Liggett, J.C. Scheerens, and M.D. Kleinhenz. 2005a. Sensory quality and mineral and glycoalkaloid concentrations in organically and conventionally grown redskin potatoes (Solanum tuberosum). J. Sci. Food Agr. 85:720-726.

Wszelaki, A.L., J.F. Delwiche, S.D. Walker, R.E. Liggett, S.A. Miller, and M.D. Kleinhenz. 2005b. Consumer liking and descriptive analysis of six varieties of organically grown edamame-type soybean. Food Qual. Pref. 16:651-658. 